Provided for non-commercial research and education use. Not for reproduction, distribution or commercial use.

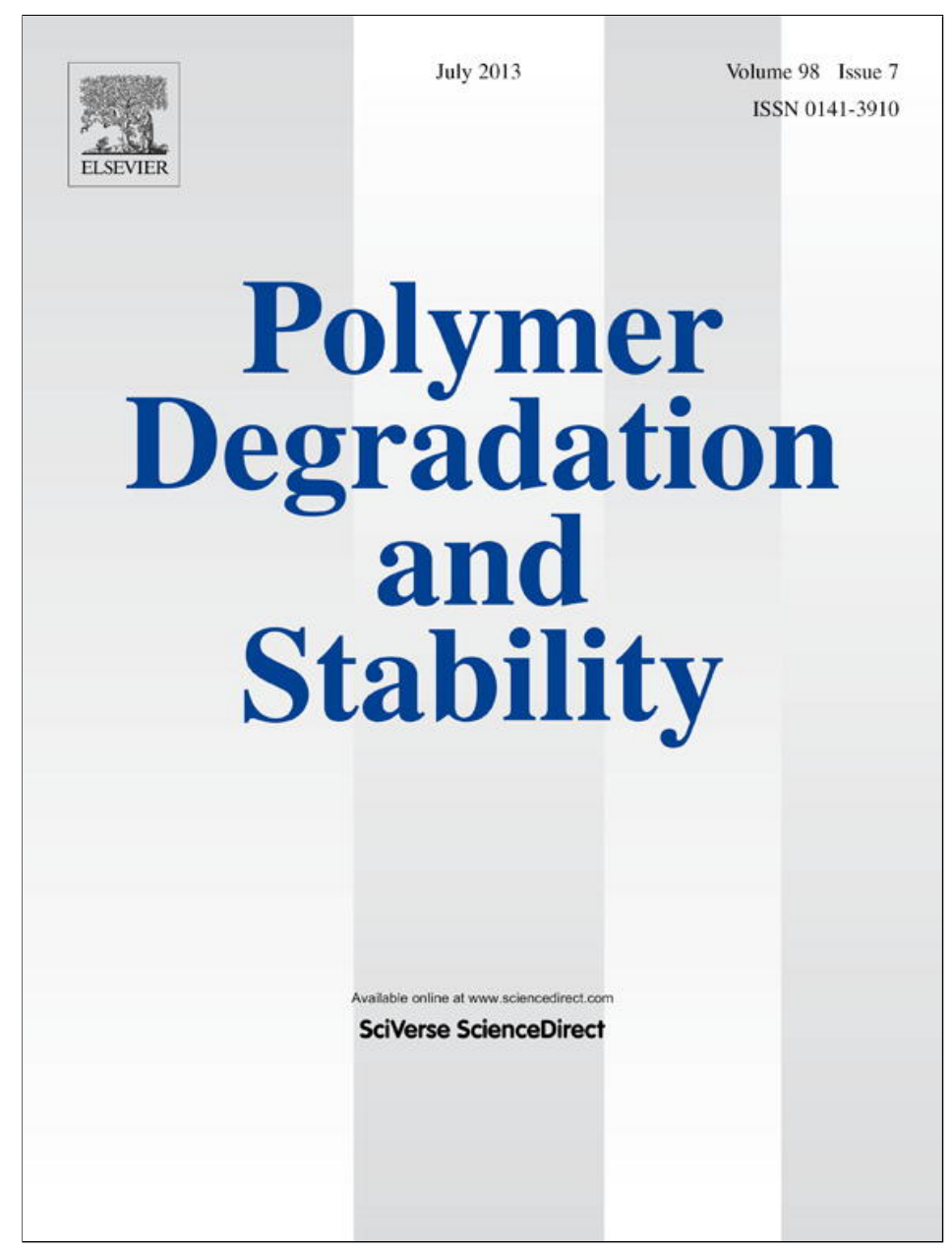

This article appeared in a journal published by Elsevier. The attached copy is furnished to the author for internal non-commercial research and education use, including for instruction at the authors institution and sharing with colleagues.

Other uses, including reproduction and distribution, or selling or licensing copies, or posting to personal, institutional or third party websites are prohibited.

In most cases authors are permitted to post their version of the article (e.g. in Word or Tex form) to their personal website or institutional repository. Authors requiring further information regarding Elsevier's archiving and manuscript policies are encouraged to visit:

http://www.elsevier.com/authorsrights 


\title{
The use of halide charged interleaves for treatment of iron gall ink damaged papers
}

\author{
Véronique Rouchon ${ }^{\mathrm{a}, *}$, Maroussia Duranton ${ }^{\mathrm{a}}$, Oulfa Belhadj ${ }^{\mathrm{a}}$, Marthe Bastier-Deroches ${ }^{\mathrm{a}}$, \\ Valéria Duplat $^{\mathrm{a}, \mathrm{b}}$, Charlotte Walbert ${ }^{\mathrm{a}}$, Birgit Vinther Hansen ${ }^{\mathrm{b}}$ \\ ${ }^{a}$ Centre de Recherche sur la Conservation des Collections, Muséum national d'Histoire naturelle, Centre national de la recherche scientifique, Ministère de la Culture et de la \\ Communication, USR3224, CP21, 36 rue Geoffroy-Saint-Hilaire, 75005 Paris, France \\ ${ }^{\mathrm{b}}$ The Royal Library, Preservation Dept., P.O. Box 2149, DK-1016 Copenhagen, Denmark
}

\section{A R T I C L E I N F O}

\section{Article history:}

Received 14 December 2012

Received in revised form

4 March 2013

Accepted 31 March 2013

Available online 17 April 2013

\section{Keywords:}

Halide

Iron gall ink

Paper

Treatment

Interleaf

Humidity

\begin{abstract}
A B S T R A C $T$
In certain conditions, iron gall inks induce substantial damages on cellulosic supports. Existing curative treatments necessitate the immersion of the documents in aqueous solutions. This implies several undesirable side effects: mechanical stress of the most damaged papers, substantial colour changes, and a drastic modification of the paper/ink composition. This work investigated an alternative treatment that consists in compressing the document between two interleaves that are charged with active compounds. When this operation is operated in moist conditions, active compounds may migrate from the interleaves to the document, and thus achieve the treatment of the paper. As high humidity conditions may additionally induce some migration of iron and acidic compounds out of the ink line, it first appeared necessary to research humidity conditions which minimize these undesirable migrations. This investigation was performed on a set of 53 original manuscripts and led us to consider that a relative humidity of $80 \%$ was quite reasonable. The second part of the paper deals with the evaluation of interleaving treatment efficiency. It was performed on laboratory samples, using several types of antioxidant halide salts ( $\mathrm{NaCl}, \mathrm{NaBr}, \mathrm{CaBr}_{2}$ ) (halides are known to act as radical scavengers). These compounds were tested separately or in combination with calcium carbonate as an alkaline buffer. The samples were made of Whatman paper that was preliminary impregnated with iron gall ink. It has shown that a charge of $2 \%$ calcium carbonate in the interleaves has no impact on the treatment efficiency, which mainly depends upon the concentration of salts, the contact pressure and the duration of the treatment. Elemental measurements show that the mobility of the salts is much higher than that of iron, suggesting the possibility to find optimum treatment conditions that minimize the iron migration risk while achieving an effective migration of halides.
\end{abstract}

(c) 2013 Elsevier Ltd. All rights reserved.

\section{Introduction}

\subsection{Iron gall inks: a major threat for western archives}

In western countries, iron gall inks were used on a significant part of archival patrimony dating from medieval times up to the beginning of the 20th century. These inks are made from a mixture [1] of iron salts (for example iron II sulphate heptahydrate), gall nuts extracts (rich in polyphenolic carboxylic acids, such as gallic

\footnotetext{
* Corresponding author. Tel.: +3314079 5303; fax: +3314079 5312.

E-mail addresses: rouchon@mnhn.fr (V. Rouchon), mduranton@mnhn.fr (M. Duranton), belhadj@mnhn.fr (O. Belhadj), marthedesroches@hotmail.fr (M. Bastier-Deroches), valeria_duplat@hotmail.com (V. Duplat), cha.walbert@ gmail.com (C. Walbert), bvh@kb.dk (B.V. Hansen).
}

acid), and gum arabic as a binder. They also contain large quantities of iron and present low $\mathrm{pH}$ values (in the range 1.5-3). As a result, they can cause a major degradation of the cellulosic carrier [2,3].

This degradation results from the superimposition of two types of phenomena: the first is mainly physical and corresponds to the migration of acidic and iron rich by-products out of the ink line [4]. It is, among others, provoked by exposure to high humidity conditions [5]. The second is mainly chemical, and occurs in the paper fibres that are in contact with the ink. This chemical degradation includes cellulose hydrolysis promoted by the acidity of the ink, and cellulose oxidation, catalysed by iron II and possibly imparted to hydroxyl radicals produced via Fenton mechanisms [6]. It was recently demonstrated that oxidation was the driving force of cellulose depolymerization induced by iron gall inks [7]. This suggests that the oxidized cellulose reorganizes through chain scissions with 
a kinetic that is much faster than that of acidic hydrolysis. In addition, it was shown that gallic acid was favouring oxidation phenomena [6], probably because of its high ability to reduce iron III into iron II $[8,9]$.

\subsection{Available treatments and their side effects}

A significant amount of work has been realized in the last decades to find chemical treatments capable of limiting iron gall ink damages. The calcium phytate process proposed in the 90's [10] has been the most widely tested [11]. Although its efficiency is well established, this treatment is rarely used, mainly because it requires immersions in aqueous solutions, which provokes drastic modifications of the paper's appearance, of its chemical composition [12-14] and mechanical damages for brittle papers [15]. These side effects are often found unacceptable.

For several decades, halides are known to decompose hydrogen peroxide [16]. This property is probably correlated to their ability to react with hydroxyl radicals thus acting as radical scavengers [17-19]. In the 2000's, a major effort was paid for the testing of non-aqueous treatments using halide products as anti-oxidants. Several studies report the efficiency of bromide and chloride compounds prepared in several organic solvents [20-25]. These results are encouraging. However, in all these studies, halide based treatments were implemented after a conventional aqueous deacidification, meaning that the global treatment remains water based with all relating side effects.

\subsection{Interleaving techniques}

Interleaving techniques consist in placing the document in contact with an interleaving paper impregnated with some active compounds. The ensemble is then pressed and kept at high relative humidity (RH) for several days. This high level of humidity provokes the migration of active compounds from the interleaves to the document, thus achieving the paper treatment. It can additionally provoke the migration of acidic and/or iron rich byproducts from the document to the interleaves [26].

Interleaving techniques were first implemented on printed documents for de-acidification purposes. Their capacity to increase the $\mathrm{pH}$ of acidic papers has been demonstrated [26] in the context of a patent deposited in 1993. The efficiency of the treatment can be improved by the presence of salts and drastically depends on the pressure and $\mathrm{RH}$ that is applied during treatment. Best results are achieved with a humidity of $97 \% \mathrm{RH}$ and a pressure above $70 \mathrm{kPa}$ (this value corresponds to a mass of $420 \mathrm{~kg}$ placed on an A4 format sheet). The possibility to use less drastic conditions was researched by Hanus et al. [27] who report that a $\mathrm{pH}$ increase of $1-$ 2 points is achievable at $92 \% \mathrm{RH}$ using interleaves that contain a high alkaline reserve (approx. 15\% of $\mathrm{CaCO}_{3}$ ) and applying a pressure of $7 \mathrm{kPa}$.

All these conditions are not realistic for original manuscripts, because (i) there is a substantial risk of ink migration if the paper is exposed to such a high humidity [5], and (ii) such a high pressure will certainly flatten the paper surface, which is detrimental to the document in the case of laid, watermarked, or dry-stamped papers. Additionally, the treatment of iron gall ink manuscripts necessitates the use of an anti-oxidant. For this purpose, halide compounds appeared promising: Interleaves charged with sodium bromide and calcium carbonate appeared efficient in limiting the paper decay provoked by iron gall inks [28,29]. More recently, the use of tetrabutylammonium bromide enabled to delay paper oxidation in a mildly alkaline environment [30] (which is unfortunately not the case of untreated original manuscripts that are acidic).

\subsection{Aim of the study}

This study aims to investigate halide based interleaving treatments using moderate conditions. Halide salts were chosen for this purpose and used separately or in combination with calcium carbonate. In addition to the aforementioned sodium bromide $(\mathrm{NaBr})$, calcium bromide $\left(\mathrm{CaBr}_{2}\right)$ was chosen because of the ability of calcium to bind carboxylic groups on cellulose chains [31], which may improve the treatment efficacy. Sodium chloride $(\mathrm{NaCl})$ was additionally included because chloride, already highlighted as an efficient anti-oxidant [21,24], is smaller than bromide, and thus may migrate more easily.

When manuscripts are exposed to high humidity conditions, brown ink compounds may additionally migrate out of the ink line and through the paper. These unaesthetic brown halos are often accompanied by a substantial migration of iron [5] and should therefore be considered as potentially detrimental to the conservation of the carrier. We thus dedicated the first part of this work to the risk assessment of these migration phenomena.

The second part of this research deals with the monitoring of the treatment. Several types of interleaves and several types of treatment were implemented in order to identify the most effective ones.

\section{Experimental}

\subsection{Methodology to evaluate the risk of ink migration related to high humidity exposure}

The risk of ink migration was evaluated on a set of 53 original manuscripts dating from 1818 to 1896, and originating from the south of France. These manuscripts were formally chosen to study the migration risk of aqueous treatments and are therefore described in detail elsewhere [5]. Several pieces of approximately $2-4 \mathrm{~cm}^{2}$ were sampled on each manuscript. Writing with a quill pen produces an uneven ink line and the line width may considerably vary along the writing according to the style of the writer. It was observed that thick lines were more prone to migration, probably because they contain a higher quantity of ink. Attention was therefore paid to sample pieces that do not only contain thin lines, but also thick lines. Visible migrations were evaluated with macro-pictures taken with a digital camera. It became obvious that a conventional light booth was too large compared to the dimensions of our samples to allow the capture of reproducible macro-pictures. We thus designed a specific three compartment light booth with a digital camera placed on the top (Fig. 1). A $4300 \mathrm{~K}$ diffuse illumination was obtained using four tungsten halogen

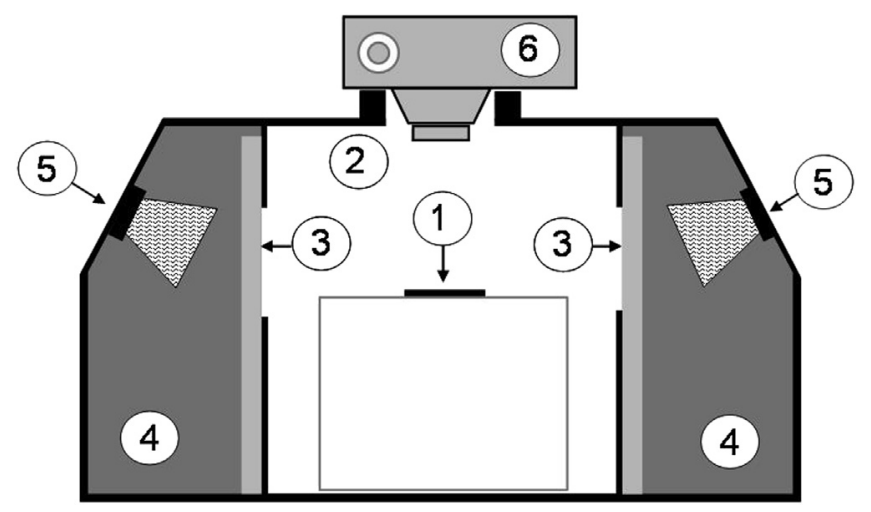

Fig. 1. Schema of the light booth. (1) Sample; (2) white walls; (3) ground glasses; (4) black walls; (5) tungsten halogen lights; (6) digital camera. 
lights that illuminate through a ground glass window a central white walled box. To absorb the backward emitted yellow light the walls of the two light compartments were painted black. The reproducibility of the lighting was checked with a $1 \times 2 \mathrm{~cm}$ colour test chart placed next to the sample.

The visible migrations of ink were identified visually by three paper conservators who have a professional expertise in paper examination. They are trained in distinguishing small colour variations on virgin paper $(1<\Delta E<3)$. The three agreed to the final evaluation.

Visible migrations were classified in two categories: "transversal migrations" concerned the transfer of coloured compounds through the paper (verso side), whereas "lateral migrations" dealt more specifically with the formation of halos around the ink line (recto side). For each category, it was necessary to define two levels of observation (Fig. 2): migrations were considered to be "obvious" when they were quickly noticeable by naked eye and "subtle" when a careful examination of macro-pictures was necessary to attest the changes.

Investigated humidity conditions ranged from $80 \%$ to $97 \% \mathrm{RH}$. At this level of humidity, there is a significant risk of mould growth if the duration of the treatment is too long. The maximum tolerable duration above which the mould risk becomes significant was chosen (Table 1). These values were estimated by the use of the Dew point calculator software (Image Permanence Institute, Rochester, USA).

In a first step of the evaluation, the samples were simply placed on a non-woven polyester film and in a climatic chamber (VC 0020, Vötsch). However, as the apparatus did not cover humidity conditions over $85 \%$ at $20{ }^{\circ} \mathrm{C}$, it appeared necessary to add water containers in the chamber in order to reach the highest humidity conditions. This method was laborious and the stabilization of the chamber was difficult to monitor. For this reason, the experiments were duplicated by the use of small enclosures with saturated salt solutions [32] (Table 1). This type of installation was more accurate and easier to manage. Throughout these experiments, temperature and $\mathrm{RH}$ were monitored with Hygro Buttons (Plug and Track, Proges Plus, precision: temperature $\pm 1{ }^{\circ} \mathrm{C}, \mathrm{RH} \pm 2 \%$ ).

\subsection{Preparation of inked samples for interleaving treatments}

Samples consisted of paper sheets impregnated with a diluted iron gall ink prepared with pure laboratory products: gallic acid monohydrate (Aldrich, 398225), $0.9 \mathrm{~g} \mathrm{~L}^{-1}$ and $\mathrm{Fe}(\mathrm{II})$ sulphate heptahydrate (Aldrich, 215422), $4 \mathrm{~g} \mathrm{~L}^{-1}$. The choice of ingredients and their concentrations are already explained elsewhere [7]. The ink was stirred in a closed vessel for 3 days until it reached a $\mathrm{pH}$ of $3.0 \pm 0.1$. The paper sheets of Whatman no $1\left(6 \times 9 \mathrm{~cm}^{2}\right)$ were immersed for $10 \mathrm{~min}$ in the ink solution, respecting a maximum ratio of $4 \mathrm{~cm}^{2}$ of paper per $1 \mathrm{~mL}$ of ink. After immersion, the excess of solution was mopped up in a similar way to that depicted in the Cobb test [33]: the paper was placed between two blotting papers and the assembled sheets were squeezed by the use of a $10 \mathrm{~kg}$ roll. This procedure enables to achieve an even distribution of the ink. The paper was then dried in ambient conditions.

\subsection{Preparation of the interleaves}

The interleaves were made of Whatman no $1\left(13 \times 13 \mathrm{~cm}^{2}\right)$ impregnated with different types of solutions as depicted in Table 2. Each impregnation was performed using $100 \mathrm{~mL}$ of solution per interleaf and each immersion lasted for $5 \mathrm{~min}$.

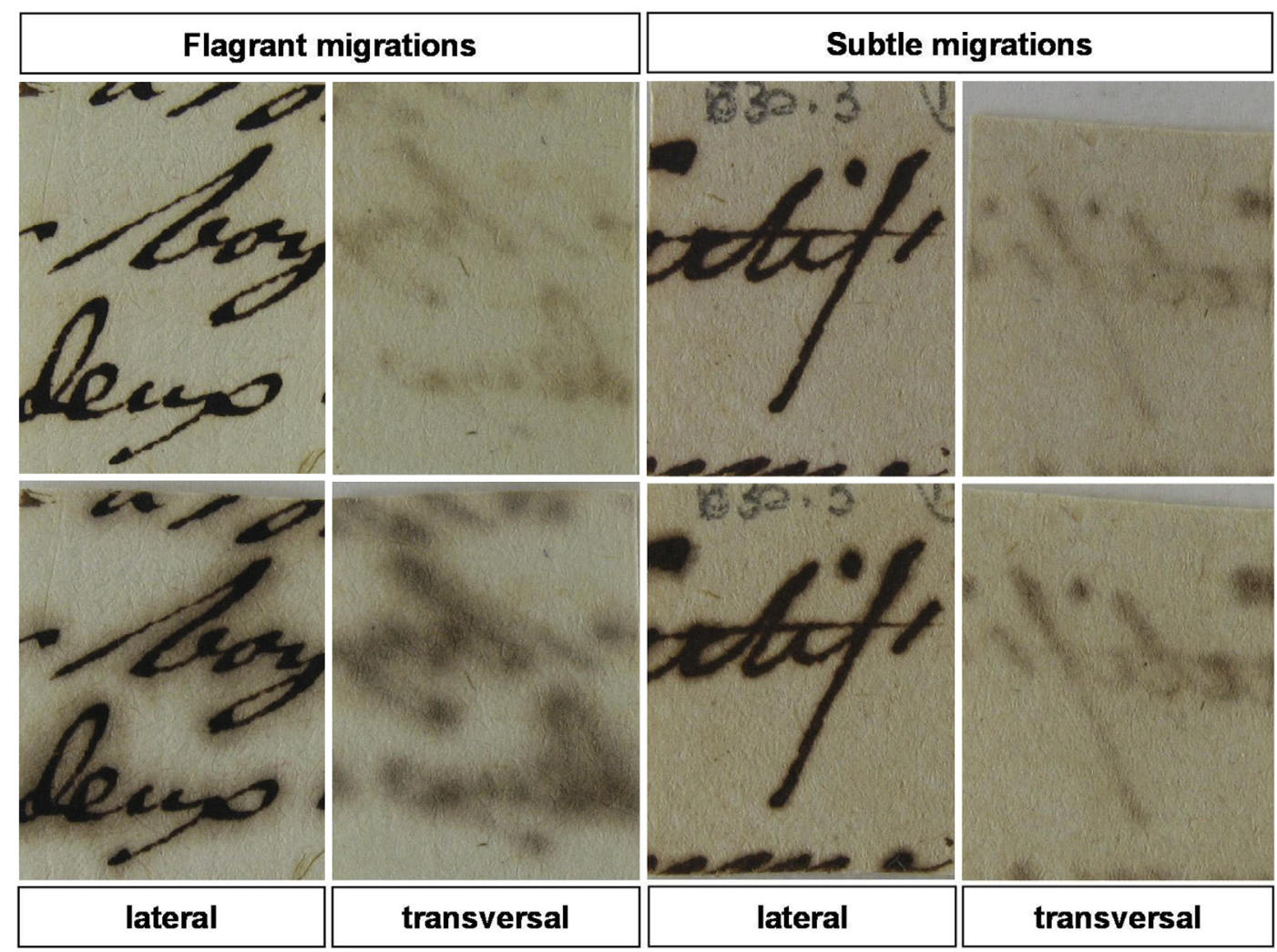

Fig. 2. The different levels of lateral and transversal migration of brown products. (For interpretation of the references to colour in this figure legend, the reader is referred to the web version of this article.) 
Table 1

Number of original samples on which brown migrations are visible. Total number of original manuscripts: 53 .

\begin{tabular}{|c|c|c|c|c|c|c|c|}
\hline \multirow[t]{2}{*}{ Relative humidity } & \multirow[t]{2}{*}{ Duration } & \multirow[t]{2}{*}{ Type of migration } & \multicolumn{3}{|c|}{ Small enclosures with saturated solutions } & \multicolumn{2}{|l|}{ Climatic chamber } \\
\hline & & & Type of salt & Lateral migrations & Transversal migrations & Lateral migrations & Transversal migrations \\
\hline \multirow[t]{3}{*}{$97 \%$} & 2 days & No & $\mathrm{K}_{2} \mathrm{SO}_{4}$ & 48 & 18 & 50 & 22 \\
\hline & & Subtle & & 5 & 30 & 3 & 28 \\
\hline & & Obvious & & 0 & 5 & 0 & 3 \\
\hline \multirow[t]{3}{*}{$93 \%$} & 4 days & No & $\mathrm{KNO}_{3}$ & 53 & 39 & 53 & 45 \\
\hline & & Subtle & & 0 & 14 & 0 & 8 \\
\hline & & Obvious & & 0 & 0 & 0 & 0 \\
\hline \multirow[t]{3}{*}{$85 \%$} & 6 days & No & $\mathrm{KCl}$ & 53 & 53 & 53 & 53 \\
\hline & & Subtle & & 0 & 0 & 0 & 0 \\
\hline & & Obvious & & 0 & 0 & 0 & 0 \\
\hline \multirow[t]{3}{*}{$80 \%$} & 14 days & No & $\mathrm{NH}_{4} \mathrm{SO}_{4}$ & 53 & 53 & 53 & 53 \\
\hline & & Subtle & & 0 & 0 & 0 & 0 \\
\hline & & Obvious & & 0 & 0 & 0 & 0 \\
\hline
\end{tabular}

Calcium carbonate $\left(\mathrm{CaCO}_{3}\right)$ was introduced in the paper using saturated solutions of calcium hydroxide $\left(\mathrm{Ca}(\mathrm{OH})_{2}\right)$. During drying, calcium hydroxide reacts with carbon dioxide, leading to the formation of calcium carbonate. However, the low solubility of calcium hydroxide $\left(2 \mathrm{~g} \mathrm{~L}^{-1}\right)$ makes impossible to deposit in one immersion the desired amount of calcium carbonate $(>2 \% \mathrm{w} / \mathrm{w})$. Impregnations with calcium hydroxide were then duplicated and the paper was dried in between in order to provoke the formation of calcium carbonate.

Solutions of halide salts were prepared with the same molar concentration of chloride or bromide $(1 \mathrm{M})$. After immersion, the sheets were placed between two Cobb blotting papers and the excess of solution was mopped up as depicted above for the preparation of inked samples.

\subsection{Implementation of the treatments and preliminary testing}

All treatments were performed at room temperature $23{ }^{\circ} \mathrm{C}$. When the papers are stacked and pressed, the time required to reach equilibrium with ambient humidity can be extremely long. In some preliminary experiments, it was found that the relative humidity within a stack of paper that is pressed for several days could remain about $10 \%$ below the ambient humidity. To avoid this discrepancy, all the material and equipment used for the contact wereis pre-conditioned for at least 2 days to obtain the desired humidity, without any pressure being applied. This step ensures that the samples are already in equilibrium with the desired moisture content before the treatment.

The contact between the samples and the interleaves was established according to the schema depicted in Fig. 3. The sample was sandwiched between two interleaves and two Cobb blotting papers. Cobb blotting papers were not used in previous studies [29], but were introduced in this work. It was expected that their

Table 2

List of interleaves and solution used. All halide solutions were prepared at $1 \mathrm{M}$ concentration of halide.

\begin{tabular}{|c|c|c|c|c|c|c|}
\hline \multirow[t]{2}{*}{ Name } & \multicolumn{2}{|l|}{ First bath } & \multicolumn{2}{|c|}{ Second bath (if any) } & \multicolumn{2}{|l|}{$\begin{array}{l}\text { Third bath } \\
\text { (if any) }\end{array}$} \\
\hline & Salt (molar conc.) & Roll & $\begin{array}{l}\text { Salt (molar } \\
\text { conc.) }\end{array}$ & Roll & $\begin{array}{l}\text { Salt (molar } \\
\text { conc.) }\end{array}$ & Roll \\
\hline $\mathrm{Ca}(\mathrm{OH})_{2}$ & $\mathrm{CaOH}_{2}(0.027)$ & No & $\mathrm{CaOH}_{2}(0.027)$ & No & - & - \\
\hline $\mathrm{NaBr}$ & $\mathrm{NaBr}(1.0)$ & Yes & - & - & - & - \\
\hline $\mathrm{NaCl}$ & $\mathrm{NaCl}(1.0)$ & Yes & - & - & - & - \\
\hline $\mathrm{CaBr}_{2}$ & $\mathrm{CaBr}_{2}(0.5)$ & Yes & - & - & - & - \\
\hline $\mathrm{Ca}(\mathrm{OH})_{2} / \mathrm{NaBr}$ & $\mathrm{CaOH}_{2}(0.027)$ & No & $\mathrm{CaOH}_{2}(0.027)$ & No & $\mathrm{NaBr}(1.0)$ & Yes \\
\hline $\mathrm{Ca}(\mathrm{OH})_{2} / \mathrm{NaCl}$ & $\mathrm{CaOH}_{2}(0.027)$ & No & $\mathrm{CaOH}_{2}(0.027)$ & No & $\mathrm{NaCl}(1.0)$ & Yes \\
\hline $\mathrm{Ca}(\mathrm{OH})_{2} / \mathrm{CaBr}_{2}$ & $\mathrm{CaOH}_{2}(0.027)$ & No & $\mathrm{CaOH}_{2}(0.027)$ & No & $\mathrm{CaBr}_{2}(0.5)$ & Yes \\
\hline
\end{tabular}

presence would prevent fluctuation of humidity if the treatment was not performed in a laboratory, but in a conservation workshop. The assembly was introduced into a polyester folder and pressed between two glass plates with a weight positioned on the top. Finally, the stack was placed in a climatic chamber (V0020, Vötsch) at the desired $\mathrm{RH}$ for several days to assure constant humidity conditions during the contact. During the treatments, the temperature and RH were controlled with Hygro Buttons (Plug and Track, Proges Plus).

\subsection{Artificial ageing and measurement of paper decay}

Before treatment, inked papers were aged in a climatic chamber (V0020, Vötsch). This causes an initial degradation of paper in order to resemble damaged manuscripts. This ageing should however remain moderate, because the samples must be re-aged after treatment to assess their evolution over time and the effectiveness of the treatment. To this respect, standard [34] moist heat ageing conditions $\left(80^{\circ} \mathrm{C}, 65 \% \mathrm{RH}\right)$ were found too drastic, since the inked paper was becoming completely brittle in less than one day. Milder ageing conditions were instead used $\left(70^{\circ} \mathrm{C}, 65 \% \mathrm{RH}\right)$ and a loss of approx. $15 \%$ of mechanical properties was achieved within 3 days. After treatment, the inked papers were separated from the interleaves and aged again in the same conditions for approximately 2 months.

As conservation treatments aim to limit physical decay of the paper, mechanical testing appeared meaningful for the evaluation of treatment efficiency. The decay of paper versus ageing was evaluated with a Zero-span tensile tester [35] (Pulmac, TS-100). The test was performed on dried papers, pre-conditioned for at least $4 \mathrm{~h}$ at $23{ }^{\circ} \mathrm{C}$ and $50 \% \mathrm{RH}$. It consists in measuring the failure load

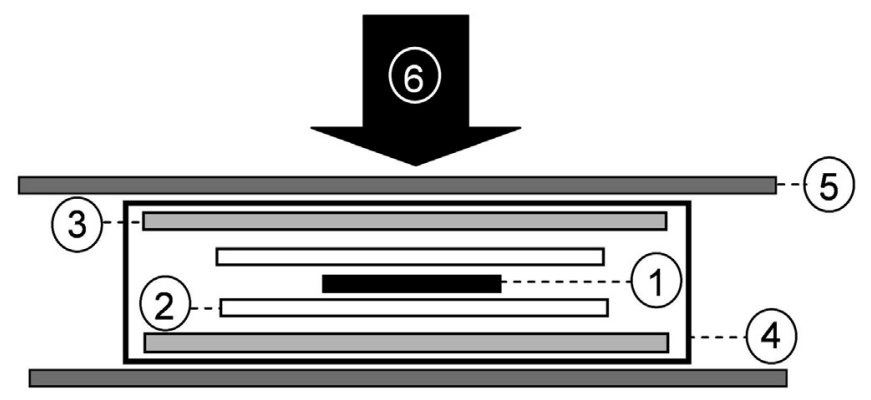

Fig. 3. Schema of interleaving treatments. The document (1), the two charged in terleaves (2), and the two blotting papers (3) are preconditioned at $80 \% \mathrm{RH}$, then placed in a plastic folder (4) and pressed between two glass plates (5) with a load (6) placed on the top. 
necessary to break a strip of paper maintained by adjacent jaws. The load is expressed in $\mathrm{kg}$ per $15 \mathrm{~mm}$ of strip width. For each sample, 10 measurements were performed and the average was calculated. Zero-span testing presents several advantages with respect to other mechanical testing: (a) it requires a small quantity of material only; (b) on Whatman no 1 paper, this test shows a better correlation with cellulose molecular mass $M_{\mathrm{w}}$ and less dispersive measurements than tensile strength testing [36].

Mechanical tests were completed with $\mathrm{pH}$ measurements performed on cold extracts prepared at ambient temperature with $0.25 \mathrm{~g}$ of paper in $12.5 \mathrm{~mL}$ of decarbonated ultrapure water [37]. The $\mathrm{pH}$ was measured $1 \mathrm{~h}$ after the immersion of the papers.

\subsection{Elemental measurement}

In order to evaluate elemental migration occurring on original manuscripts after exposure to high humidity conditions, a scanning electron microscope coupled with a dispersive X-ray detection spectrometer (SEM/EDS, JEOL JSM-5410LV, Oxford Instrument Link Pentafet) was used. Specific attention was paid to the elements that are originally contained in the ink (mainly iron, sulphur, potassium, and calcium). Experimental conditions used for elemental mapping were the following: $30 \mathrm{keV}$ beam, diaphragm 2, low vacuum $20 \mathrm{~Pa}$, no sample preparation, acquisition time between one and $3 \mathrm{~h}$. References of iron sulphate impregnated papers (whose iron content was preliminary determined by atomic absorption spectrometry [38]) were used to estimate the low detection limit of SEM/ EDS. It was close to $2 \mathrm{mg}$ of iron per gram of paper, a value significantly superior to the residual average amount of iron deposited in the paper during its manufacture (estimated to be in the range of $0.1-0.4 \mathrm{mg} / \mathrm{g}$ on well preserved papers [39]).

The possible migration of a low amount of iron (below $2 \mathrm{mg} \mathrm{g}^{-1}$ ) was further investigated with a colour test, using the property of Bathophenanthroline (a water insoluble indicator) of forming a purple complex/precipitate with iron II ions [40,41]. Bathophenanthroline impregnated papers (solution used for the impregnation: $1.6 \mathrm{~g} \mathrm{~L}^{-1}$ in $99.9 \%$ ethanol) are largely used in the field of paper conservation for the identification of iron gall inks $[42,43]$ and for the monitoring of the phytate treatment [11]. In this study, we used Bathophenanthroline impregnated papers that are stamped with an iron gall ink. These samples, which detailed preparation can be found elsewhere [44], were specifically designed to identify the risk of iron migration when aqueous adhesives are applied on manuscripts. They are capable to highlight the presence of very small concentrations of iron II, close to $0.06 \mathrm{mg} \mathrm{g}^{-1}[11]$.

Finally, in order to determine the average elemental contents of inked papers and interleaves, the papers were mineralized in concentrated acid. Elemental concentration in iron, calcium, sodium, bromide, and chloride was measured by ICP-AES (ICAP 6300, Thermofisher Scientific). Elemental concentration in sulphur was evaluated with a UV fluorescence nitrogen analyser (TN/TS 3000, Thermofisher Scientific), after the total combustion of approx. $5 \mathrm{mg}$ of samples at $1000^{\circ} \mathrm{C}$ in the presence of argon and oxygen (in order to assure the conversion of sulphur into sulphur dioxide). All samples were triplicated and the average was considered.

\section{Results}

\subsection{Evaluation of visible side effects induced by high humidity exposure}

The methodology used for the evaluation of migration of brown products appears satisfactorily reproducible as the results of the two sets of measurements are similar (see Table 1: small enclosures and climatic chamber), despite some small differences that are probably attributable to the heterogeneity of the manuscripts. When exposed at humidity over $90 \% \mathrm{RH}$, a significant number of documents are subjected to migration phenomena. On these samples, the condensation of water in the micro(nano)-porous structure of paper is probably sufficient to provoke the dissolution and the migration of ink by-products [45]. On the contrary, the 53 original samples could be exposed to $80 \% \mathrm{RH}$ for 14 days or to $85 \%$ $\mathrm{RH}$ for 6 days without any visible migration on the recto and on the verso of the ink lines.

Elemental mappings were performed on a selection of samples. On all samples showing obvious visible migrations, the distribution of iron was systematically superimposing that of brown halos, showing that iron migrates with brown products. The samples on which no elemental migration of iron was noticeable corresponded to those showing no visible change or the most subtle of the visible migrations. On these samples, the iron migration (if any) was too low to be highlighted by SELM/EDS.

These observations are consistent with a previous work dealing with the evaluation of aqueous treatment side effects [5] which showed that iron migrations, when detected by SEM/EDS, were systematically superimposing that of brown products.

In order to estimate if a low amount of iron may migrate at $80 \%$ $\mathrm{RH}$, we opted for a more sensitive (although not quantitative) methodology using Bathophenanthroline impregnated papers. On these samples, it was confirmed (Fig. 4) that there is a significant risk of iron migration at $97 \% \mathrm{RH}$ for 1 day, whereas no iron migration could be observed at $80 \%$ RH for 10 days.

It could be objected that a great variety of iron gall inks exist and some may exhibit a different behaviour from that of our reduced selection. It is however not realistic to test all kinds of original manuscripts before designing a conservation treatment. Our observations are consistent and led us to consider that the risk of ink migration remains relatively low during an exposure at $80 \% \mathrm{RH}$ for 10 days.

\subsection{Control of the initial composition of the interleaves}

In newly prepared interleaves, elemental concentrations of halides (Table 3) are close to $1000 \pm 200 \mu$ mole $^{-1}$ and quite similar from one salt to another. Moreover, the stoichiometric ratios between the elements deposited in the interleaves remain close to those of impregnating solutions. This observation is accounted to the fact that Whatman paper is both a porous and absorbent material that retains a certain amount of solution when removed from the baths. This amount is estimated to be $1.15 \mathrm{~mL}$ of solution per gram of paper when a Cobb roll is used for the removal of the surplus of solution (impregnation with $\mathrm{NaBr}, \mathrm{CaBr}_{2}$, and $\mathrm{NaCl}$ ). This amount was used to estimate a concentration of halide of $1150 \mu$ mole $\mathrm{g}^{-1}$, a value close to the average aforementioned measurements $\left(1000 \pm 200 \mu\right.$ mole $\left.\mathrm{g}^{-1}\right)$. It is also reasonable to consider that interleaves elemental contents correspond to the deposits brought by the solution that remains in the paper after immersion.

This observation is not valid when considering calcium contents. After impregnation with $\mathrm{Ca}(\mathrm{OH})_{2}$ solutions, the surplus of water is not removed and the remaining solution $(2.7 \mathrm{~mL}$ per gram of paper) should theoretically deposit $73 \mu$ mole $\mathrm{g}^{-1}$ of calcium. When considering, on respectively " $\mathrm{Ca}(\mathrm{OH})_{2}$ ", " $\mathrm{Ca}(\mathrm{OH})_{2} / \mathrm{NaBr}$ " and " $\mathrm{Ca}(\mathrm{OH})_{2} / \mathrm{NaCl}$ " interleaves, that the deposits of the two successive $\mathrm{Ca}(\mathrm{OH})_{2}$ solutions are superimposing, we may estimate the final calcium content at $146 \mu$ mole $\mathrm{g}^{-1}$, a value inferior to our measurements (respectively 270, 220 and $240 \mu$ mole $^{-1}$ ). This point is consistent with previous observations formulated on papers impregnated with other types of calcium containing solutions [11] 

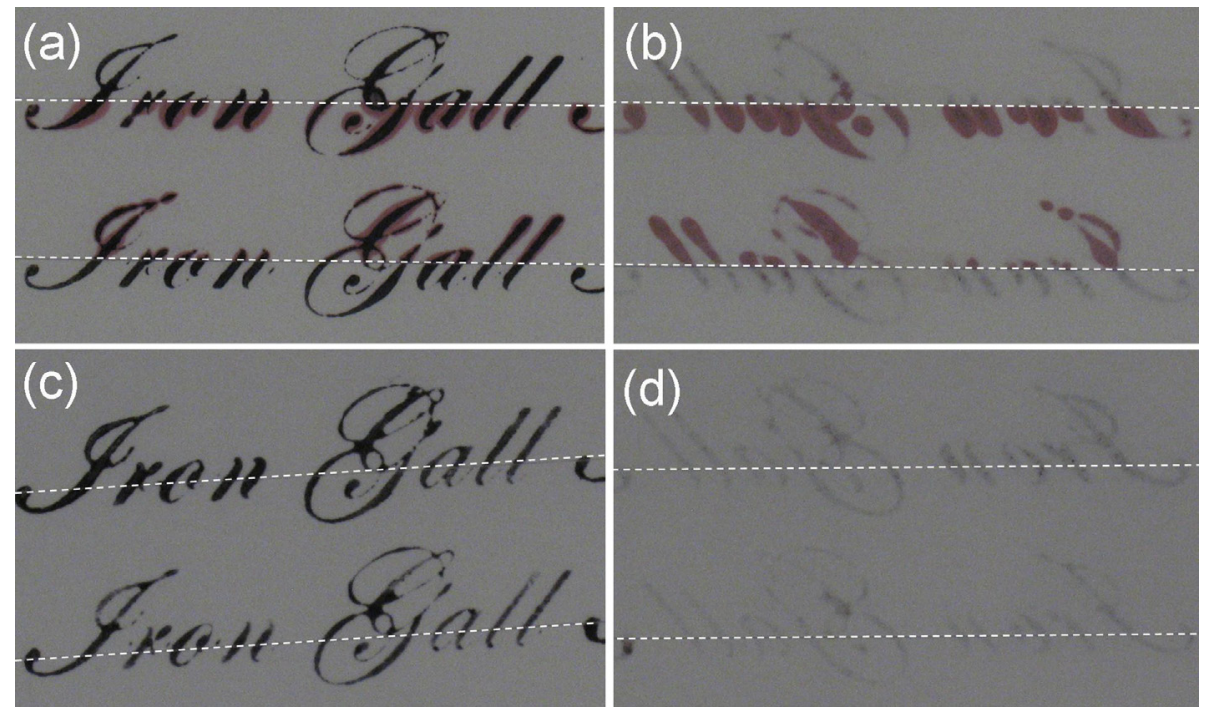

Fig. 4. Migrations of iron II detected by the use of the Bathophenanthroline test paper. These papers were stamped with iron gall ink then cut into several pieces. The central parts were exposed to high humidity conditions, whereas the upper and lower parts were not treated. (a): $97 \%$ RH, 1 day, recto side; (b): $97 \%$ RH, 1 day, verso side; (c): $80 \%$ RH, 10 days, recto side; (d): $80 \%$, 10 days, verso side.

and highlights a strong interaction between calcium and cellulose during immersion.

\subsection{Preliminary testing of efficiency}

Following the results of previous work [29], some primary treatments were performed during a 10 day period at $80 \% \mathrm{RH}$, using a global pressure of $2.5 \mathrm{kPa}$ ( $15 \mathrm{~kg}$ on an A4 format sheet). In these conditions, the " $\mathrm{Ca}(\mathrm{OH})_{2} / \mathrm{NaBr}$ " interleaves were inefficient in delaying the paper decay, probably because (a) the interleaves prepared in Vinther Hansen's work were more concentrated than this series (they were not pressed with a Cobb roll), and (b) the addition of Cobb blotting papers during the contact enables salts to migrate in an additional medium and thus less in the inked paper.

The treatment became efficient when repeated at a higher humidity $(95 \% \mathrm{RH})$. However, we meanwhile found that such a high humidity was provoking a substantial migration of iron and coloured compounds out of the ink line. This point was clearly prohibitive.

It was therefore decided to remain at $80 \% \mathrm{RH}$ and to investigate higher pressures. However, as the flattening of laid, watermarked or dry-stamped papers was undesirable, high pressure values such as those used for de-acidification treatments [26,27] were not chosen. It was found preferable to opt for an intermediate pressure of $4 \mathrm{kPa}(25 \mathrm{~kg}$ on an A4 format sheet).

Table 3

Elemental composition of the interleaves before treatments. Elemental concentrations are measured with a precision of $\pm 10 \%$. "Whatman" refers to virgin Whatman no 1 paper. Interleaves were prepared as depicted in Table 2.

\begin{tabular}{|c|c|c|c|c|}
\hline \multirow[t]{2}{*}{ Name } & \multicolumn{4}{|c|}{$\begin{array}{l}\text { Elemental concentration (micromole per gram of } \\
\text { paper) }\end{array}$} \\
\hline & $\mathrm{Na}$ & $\mathrm{Ca}$ & $\mathrm{Br}$ & $\mathrm{Cl}$ \\
\hline Whatman & 2 & 1 & $<0.5$ & $<0.1$ \\
\hline $\mathrm{Ca}(\mathrm{OH})_{2}$ & - & 270 & - & - \\
\hline $\mathrm{NaBr}$ & 740 & - & 860 & - \\
\hline $\mathrm{NaCl}$ & 1040 & - & - & 980 \\
\hline $\mathrm{CaBr}_{2}$ & - & 550 & 1050 & - \\
\hline $\mathrm{Ca}(\mathrm{OH})_{2} / \mathrm{NaBr}$ & 980 & 220 & 1160 & - \\
\hline $\mathrm{Ca}(\mathrm{OH})_{2} / \mathrm{NaCl}$ & 1160 & 240 & - & 1200 \\
\hline $\mathrm{Ca}(\mathrm{OH})_{2} / \mathrm{CaBr}_{2}$ & - & 770 & 830 & - \\
\hline
\end{tabular}

\subsection{Evaluation of the treatment efficiency}

The interleaves depicted above were firstly used to implement the treatment at $80 \% \mathrm{RH}$, with a pressure of $4 \mathrm{kPa}$, and testing respectively a short exposure period (2 days) and a longer exposure period (10 days). The duration of the exposure appears a determinant parameter: 2 day exposures were inefficient in delaying the loss of mechanical properties (Fig. 5a), and in increasing the $\mathrm{pH}$ of the paper which remains close to $4.0 \pm 0.3$ (not shown). On the contrary, when the duration of exposure is extended to 10 days (Fig. 5b), some treatments were limiting the loss of mechanical properties. The best results were achieved with sodium chloride impregnated interleaves ("NaCl" and " $\mathrm{Ca}(\mathrm{OH})_{2} / \mathrm{NaCl}$ ") whereas calcium carbonate and calcium bromide impregnated interleaves (" $\mathrm{Ca}(\mathrm{OH})_{2}$ ", " $\mathrm{CaBr}_{2}$ " and " $\mathrm{Ca}(\mathrm{OH})_{2} / \mathrm{CaBr}_{2}$ ") seemed to have no effect at all.

Table 4 shows $\mathrm{pH}$ measurements performed on inked paper after treatment and at the end of artificial ageing. First, the $\mathrm{pH}$ of

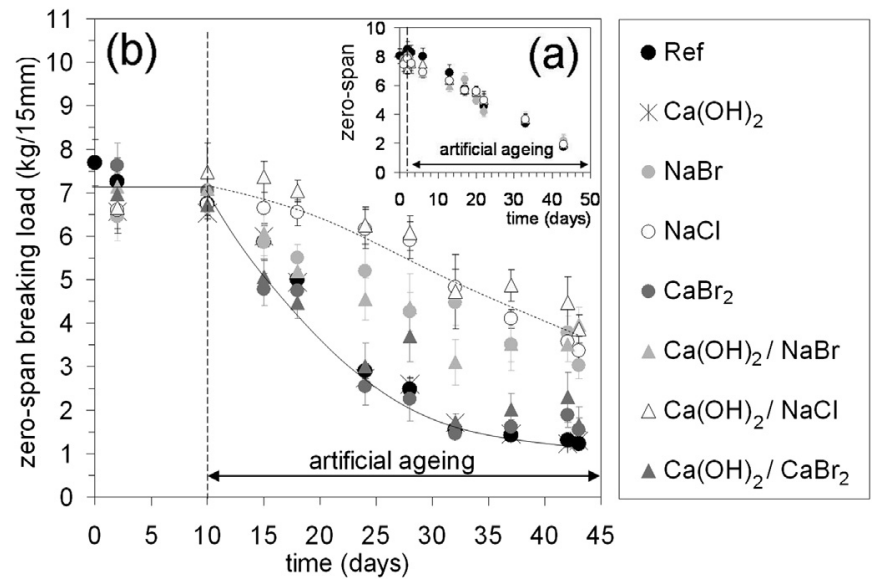

Fig. 5. Mechanical decay versus time of samples treated at $80 \%$ RH. All samples were first maintained at $23^{\circ} \mathrm{C}, 80 \% \mathrm{RH}$ during the treatments then aged artificially at $70^{\circ} \mathrm{C}$, $65 \% \mathrm{RH}$. All treatments were performed using a pressure of $4 \mathrm{kPa}$ for a period of 2 days (a) or 10 days (b). The graph plots the average of ten measurements. The error bars correspond to the standard deviation of these measurements. 
Table 4

$\mathrm{pH}$ and elemental composition of the inked samples after treatment. The treatments were performed for 10 days, with a pressure of $4 \mathrm{kPa}$, and using the interleaves depicted in Table 3. Precision of $\mathrm{pH}$ measurements \pm 0.5 ; precision of elemental measurements $\pm 15 \%$. The $\mathrm{pH}$ was measured after treatment and after 43 days of artificial ageing $\left(70{ }^{\circ} \mathrm{C}, 65 \% \mathrm{RH}\right)$. "No salt" refers to reference inked papers that where treated with virgin Whatman papers.

\begin{tabular}{|c|c|c|c|c|c|c|}
\hline \multirow{2}{*}{$\begin{array}{l}\text { Type of interleaf } \\
\text { used for the } \\
\text { treatment }\end{array}$} & \multicolumn{2}{|l|}{$\mathrm{pH}$} & \multicolumn{4}{|c|}{$\begin{array}{l}\text { Concentration (micromole } \\
\text { per gram of paper) }\end{array}$} \\
\hline & $\begin{array}{l}\text { After } \\
\text { treatment }\end{array}$ & After ageing & $\mathrm{Na}$ & $\mathrm{Ca}$ & $\mathrm{Br}$ & $\mathrm{Cl}$ \\
\hline No salt & 3.8 & 4.1 & 2 & 1 & $<0.5$ & $<0.1$ \\
\hline $\mathrm{CaOH}_{2}$ & 3.9 & 4.0 & - & 2.9 & - & - \\
\hline $\mathrm{NaBr}$ & 4.3 & 5.3 & 290 & - & 200 & - \\
\hline $\mathrm{NaCl}$ & 4.9 & 5.0 & 270 & - & - & 420 \\
\hline $\mathrm{CaBr}_{2}$ & 3.8 & 4.7 & - & 47 & 150 & - \\
\hline $\mathrm{Ca}(\mathrm{OH})_{2} / \mathrm{NaBr}$ & 4.3 & 5.6 & 300 & 2.5 & 280 & - \\
\hline $\mathrm{Ca}(\mathrm{OH})_{2} / \mathrm{NaCl}$ & 5.9 & 5.1 & 250 & 2.5 & - & 520 \\
\hline $\mathrm{Ca}(\mathrm{OH})_{2} / \mathrm{CaBr}_{2}$ & 3.8 & 5.0 & - & 75 & 310 & - \\
\hline
\end{tabular}

untreated samples (3.8) remained constant with ageing, contrarily to the commonly acknowledged idea that acidic papers grow more acidic as they age [46]. Second, " $\mathrm{Ca}(\mathrm{OH})_{2}$ " interleaves appeared absolutely inefficient in raising up the $\mathrm{pH}$ of inked papers or delaying its degradation. More generally, the $\mathrm{pH}$ increase of inked papers is not related to the presence of calcium carbonate in interleaves and the addition of calcium carbonate does not appear to have any positive impact.

For halide treatments that seem to have no effect ("CaBr 2 " and " $\mathrm{Ca}(\mathrm{OH})_{2} / \mathrm{CaBr}_{2}$ "), the $\mathrm{pH}$ after treatment remains close to its initial value (3.8), but rises up during ageing. For the most effective halide treatments ("NaCl" and " $\mathrm{Ca}(\mathrm{OH})_{2} / \mathrm{NaCl}$ "), the $\mathrm{pH}$ significantly increases during treatment up to a range of 4.9-5.9 and remains stable through ageing. Thus the treatment efficiency seems, to a certain extent, to be correlated to an increase of $\mathrm{pH}$ during treatment. Should this $\mathrm{pH}$ increase be considered as the major explanation of the treatment efficiency? Is it simply a side effect? Surprisingly, after 43 days of artificial ageing, all papers treated with halide containing interleaves present the similar $\mathrm{pH}$ values $(5.1 \pm 0.5)$ (Table 4$)$ regardless to the efficiency of the treatment.

The comparison of elemental concentration of inked samples after treatment (Table 4) with that of interleaves before treatment (Table 3) shows that the migration of halides is substantial: for instance, the average amount of halide migrating to inked samples during the treatment with " $\mathrm{Ca}(\mathrm{OH})_{2} / \mathrm{NaCl}$ " interleaves $\left(520 \mu\right.$ mole $\mathrm{g}^{-1}$ ) represents approximately $40 \%$ of the initial concentration of one interleaf (see Table 3, $1200 \mu$ mole $\mathrm{g}^{-1}$ ). Considering that the samples were sandwiched between two interleaves, we can deduce that approx. $20 \%$ of chlorine present in each interleaf migrates to the inked paper, thus illustrating the mobility of chloride ions. The mobility of bromine and sodium is slightly inferior but remains important, as approx. $10 \%-15 \%$ of the initial amount of bromine and sodium present in each interleaf migrates to inked samples. On the contrary, the mobility of calcium is much lower: considering the interleaves " $\mathrm{Ca}(\mathrm{OH})_{2}$ ", which are supposed to contain calcium carbonate, less than $1 \%$ of the initial amount of calcium migrates into the samples. This ratio increases up to approx. $5 \%$ in the case of " $\mathrm{Ca}(\mathrm{OH})_{2} / \mathrm{CaBr}_{2}$ " and " $\mathrm{CaBr}_{2}$ " interleaves, probably because calcium bromide dissociates more easily than calcium carbonate. However, we can notice that inked papers treated with " $\mathrm{Ca}(\mathrm{OH})_{2} / \mathrm{CaBr}_{2}$ " and " $\mathrm{CaBr}_{2}$ " interleaves contain, after treatment, between 3 and 4 times less calcium than bromine, meaning that calcium, when liberated by the dissociation of calcium bromide, are less inclined for migration than bromine.

On Fig. 5 it can be seen that the addition of calcium carbonate in the interleaves does not affect the behaviour of treated samples.
Table 5

Iron and sulphur concentration of inked samples and interleaves after treatment. Elemental concentrations are measured with a precision of $\pm 20 \%$.

\begin{tabular}{lllc}
\hline & & \multicolumn{2}{l}{$\begin{array}{l}\text { Micromole per gram } \\
\text { of paper }\end{array}$} \\
\cline { 3 - 4 } & & $\mathrm{Fe}$ & $\mathrm{S}$ \\
\hline Inked samples & - & 16 & 15 \\
Interleaves (after & $\mathrm{Ca}(\mathrm{OH})_{2}$ & 0.14 & 0.9 \\
treatment) & $\mathrm{NaBr}$ & 0.30 & 1.6 \\
& $\mathrm{NaCl}$ & 0.09 & 1.1 \\
& $\mathrm{CaBr} 2$ & 0.09 & 0.4 \\
& $\mathrm{Ca}(\mathrm{OH})_{2} / \mathrm{NaBr}$ & 0.20 & 2.0 \\
& $\mathrm{Ca}(\mathrm{OH})_{2} / \mathrm{NaCl}$ & 0.13 & 1.0 \\
& $\mathrm{Ca}(\mathrm{OH})_{2} / \mathrm{CaBr}_{2}$ & 0.13 & 0.6 \\
\hline
\end{tabular}

This is coherent with $\mathrm{pH}$ and elemental measurements (Table 4) which show, as discussed above, that calcium does not migrate easily to the inked paper. For this reason, the " $\mathrm{Ca}(\mathrm{OH})_{2} / \mathrm{CaBr}_{2}$ ", " $\mathrm{Ca}(\mathrm{OH})_{2} / \mathrm{NaBr}$ ", and " $\mathrm{Ca}(\mathrm{OH})_{2} / \mathrm{NaCl}$ " interleaves will be removed from the rest of our work.

Considering that a large proportion of halide migrates from the interleaves to the inked paper, one can a priori not exclude that some proportion of iron and sulphur migrates from the inked paper to the interleaves. The concentrations of iron measured in the interleaves after treatment, reported in Table 5, show that approx. $0.6 \%-2 \%$ of the initial amount of iron present in the inked samples migrates to each interleaf, meaning that the iron that is present in the inked samples is much less mobile than halides. This point is crucial, because it shows that it should be possible to find experimental conditions that minimize the risk of original inks migration while allowing halides migration.

It can be seen in Table 5 that sulphur migrates more easily than iron: $3 \%-13 \%$ of the initial amount of sulphur present in inked samples migrates to each interleaf. This point corroborates elemental measurements previously performed on laboratory [47] and original samples [48], that systematically pointed out a subsequent migration of sulphate ions out of the ink lines.

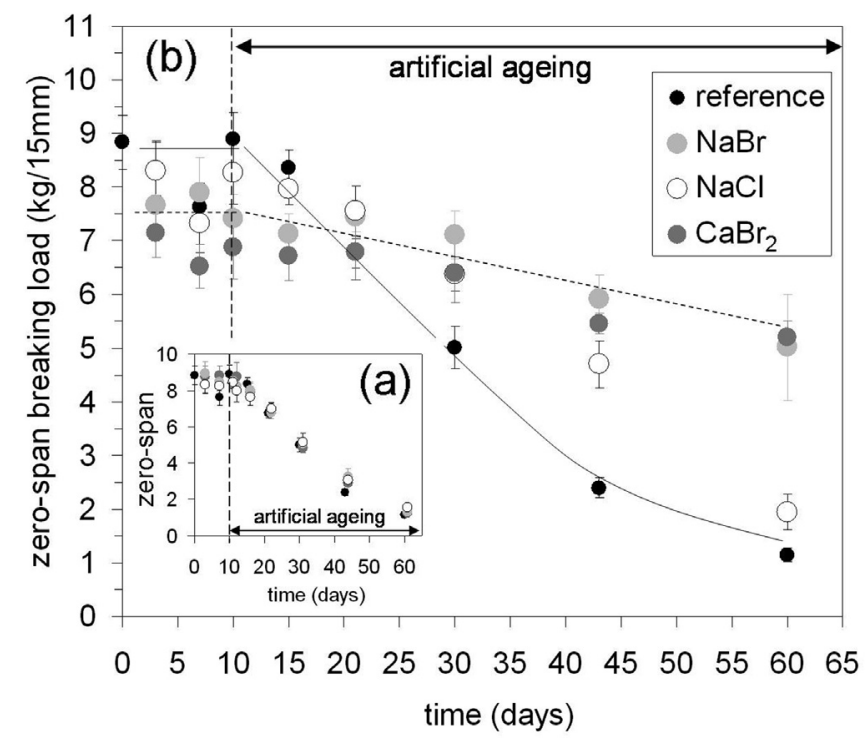

Fig. 6. Influence of the concentration of salts in the interleaves. All samples were first maintained at $23{ }^{\circ} \mathrm{C}, 80 \% \mathrm{RH}$ during the treatments then aged artificially at $70{ }^{\circ} \mathrm{C}, 65 \%$ $\mathrm{RH}$. All treatments were performed using a pressure of $4 \mathrm{kPa}$. Concentration of salt used for the impregnation of the interleaves: $0.2 \mathrm{M} \mathrm{(a)}$ and $5 \mathrm{M}(\mathrm{b})$. The graph plots the average of ten measurements. The error bars correspond to the standard deviation of these measurements. 


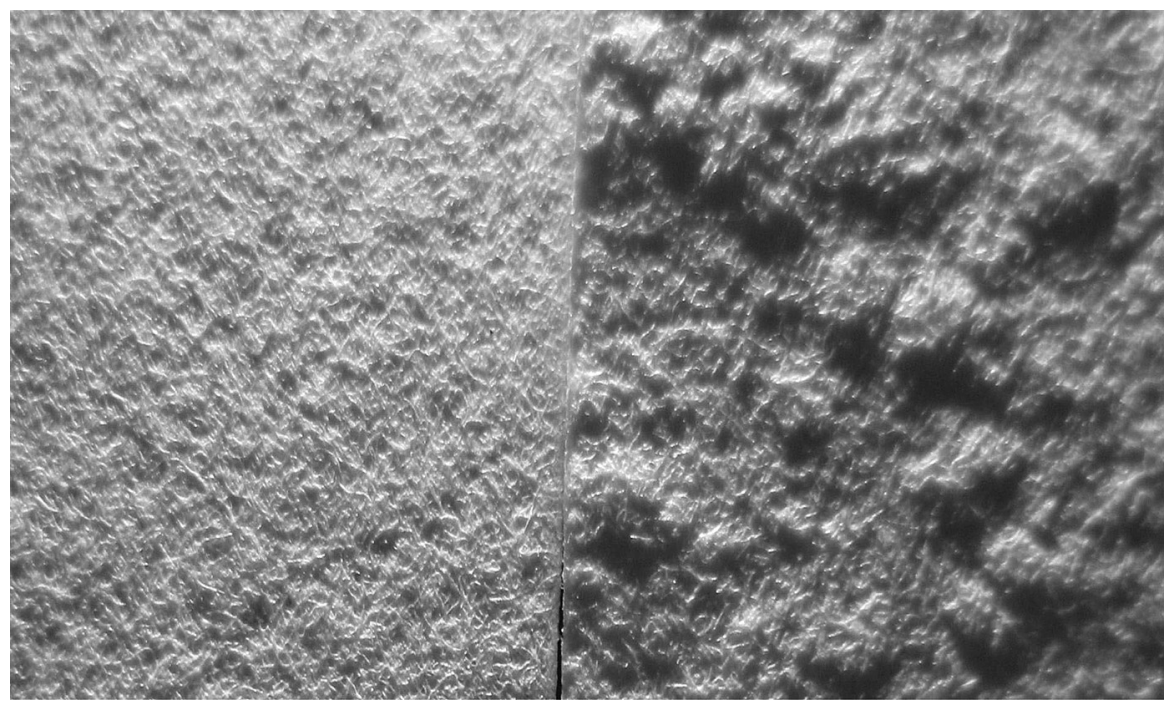

Fig. 7. Aspect of the paper surface under grazing light. Left: virgin Whatman paper; right: interleaf prepared with a $5 \mathrm{M} \mathrm{NaCl} \mathrm{solution}$.

\subsection{Influence of the concentration of halide in the interleaves}

In order to evaluate if the efficiency of the treatment could be improved by the use of more concentrated interleaves or if it remains efficient with the use of more diluted interleaves, two new sets of interleaves were prepared, in the same way as depicted above, yet using 5 times more concentrated (diluted) solutions. The treatments were implemented with the same conditions as above (80\% RH, 10 days, $4 \mathrm{kPa}$ ).

The results obtained with these new sets of interleaves are summarized in Fig. 6. Diluted interleaves appeared totally inefficient in delaying the paper decay (Fig. 6a). On the contrary, the use of more concentrated interleaves significantly improved the efficiency of the treatment (Fig. 6b). " $\mathrm{CaBr}_{2}$ " and "NaBr" interleaves give better results: after 60 days of artificial ageing, the zero-span breaking load of treated samples has decreased by approx. $30 \%$ while it reaches its minimum value on untreated samples.

Independently of the salt that is considered, the treatments with concentrated interleaves ( $5 \mathrm{M}$ solutions) provoked on all inked samples a substantial $\mathrm{pH}$ increase, up to values ranging from 6.0 to 6.5. Contrary to our previous observations (see Section 3.4 and Table 4), the $\mathrm{pH}$ of treated papers decreased with ageing and reached $\mathrm{pH}$ values ranging 5.0 to 5.5 after 60 days of artificial ageing. Surprisingly, these values are similar to those presented in Table 4 (pH after ageing).

Despite the fact that concentrated interleaves prepared with $5 \mathrm{M}$ solutions make the treatment more efficient, the work was not pursued with such high concentrations, and this for two reasons: first, in the case of $\mathrm{NaCl}$, the high concentration of salt provoked some mechanical tensions probably attributable to crystalline formation. The paper surface became uneven (Fig. 7). This point jeopardized the treatment efficacy as it was not possible to achieve a satisfactory contact (see Fig. 6 " $\mathrm{NaCl}$ " treatment). Second, it can be observed in Fig. 6 that the treatment modifies the initial mechanical properties of the paper: the initial zero-span breaking load is close to $8.2 \pm 0.5$ on reference Whatman paper, and decreases slightly down to $7.4 \pm 0.5$ on the paper that are treated by "NaBr" and " $\mathrm{CaBr}_{2}$ " interleaves. This modification of mechanical properties, which probably results from a large migration of salts, is not researched on original manuscripts.

\section{Conclusions}

This work was undertaken to evaluate the possibility of implementing interleaving techniques for the treatment of papers damaged by iron gall inks. We first evaluated the risk of ink migration at high humidity conditions on a set of 53 original manuscripts and found that an exposure at $80 \% \mathrm{RH}$ for 10 days was satisfactorily minimizing this risk. Treatments were thus implemented at this humidity level.

It was shown that halides easily migrate from the interleaves to the treated paper and that they are capable to delay the paper decay, even in middle acidic environment. This stabilizing effect might be correlated to an increase of $\mathrm{pH}$ during the treatment, but is not accounted to the calcium carbonate contained in the interleaves. Indeed, the presence of calcium carbonate in the interleaves did not have any measurable effect on the treatment efficiency, probably because calcium carbonate does not dissolve easily during the treatment.

In this work, several factors were tested for a better monitoring of the treatment: firstly the treatment should be sufficiently long and cannot be reduced from 10 days to 2 days. Secondly, the concentration of salts in the interleaves should be sufficiently high: using $0.2 \mathrm{M}$ solutions for the preparation of interleaves makes the treatment inefficient; using $1 \mathrm{M}$ solutions makes the treatment partially efficient for some salts; using $5 \mathrm{M}$ solutions makes the treatment efficient for all salts but leads to substantial undesirable side effects on some samples. These considerations show that the concentrations of halides which migrate to the paper during the treatments is a key factor for the monitoring of the treatment efficiency.

Encouragingly, we noticed that the migration of iron from the samples to the interleaves was largely less than that of halide compounds from the interleaves to the sample. Experimental conditions should be found that minimize the migration risk of iron while enabling that of halides.

It appears now necessary to pursue the effort by examining the effect of the treatment on original valueless manuscripts. Their composition is more complex than that of our laboratory samples, which may raise new difficulties: the paper size for instance may drastically change migration phenomena. Finally, side effects, such as the formation of salt efflorescence, or the flattening of laid, watermarked, or dry-stamped papers should be evaluated on 
original valueless manuscripts before implementing the treatment on valuable collections.

\section{Acknowledgement}

This study was funded by the French National Program of Research for Cultural Heritage (PNRCC 2010-2011).

\section{References}

[1] Stijnman A. Iron gall inks in history: ingredients and production. In: Kolar J, Strlic M, editors. Iron gall inks: on manufacture, characterisation, degradation and stabilisation. Ljubljana: National and University Library; 2006. p. 25-68.

[2] Kolar J, Strlic M, editors. Ageing and stabilisation of paper. Ljubljana: National and University Library; 2005.

[3] Banik G, Weber H, editors. Tintenfrassschäden und ihre Behandlung. Stuttgart: Kohlhammer; 1999.

[4] Remazeilles C, Rouchon Quillet V, Bernard J, Calligaro T, Dran JC, Salomon J, et al. Influence of gum arabic on iron gall ink corrosion, part II: observation and elemental analysis of originals. Restaurator 2005;26:118-33.

[5] Rouchon V, Durocher B, Pellizzi E, Stordiau-Pallot J. The water sensitivity of iron gall ink and its risk assessment. Stud Conserv 2009;54:236-54.

[6] Strlic M, Radovic T, Kolar J, Pihlar B. Anti- and prooxidative properties of gallic acid in Fenton-type systems. J Agric Food Chem 2002;50:6313-7.

[7] Rouchon V, Duranton M, Burgaud C, Pellizzi E, Lavedrine B, Janssens K, et al. Room-temperature study of iron gall ink impregnated paper degradation under various oxygen and humidity conditions: time-dependent monitoring by viscosity and X-ray absorption near-edge spectrometry measurements. Anal Chem 2011;83:2589-97.

[8] Burgaud C, Rouchon V, Refait P, Wattiaux A. Mossbauer spectrometry applied to the study of laboratory samples made of iron gall ink. Appl Phys A Mater Sci Process 2008;92:257-62.

[9] Burgaud C, Rouchon V, Wattiaux A, Bleton J, Sabot R, Refait P. Determination of the $\mathrm{Fe}(\mathrm{II}) / \mathrm{Fe}(\mathrm{III})$ ratio in iron gall inks by potentiometry: a preliminary study. J Electroanal Chem 2010;650:16-23.

[10] Neevel JG. Phytate: a potential conservation agent for the treatment of ink corrosion caused by iron gall inks. Restaurator 1995;16:143-60.

[11] Rouchon V, Pellizzi E, Duranton M, Vanmeert F, Janssens K. Combining XANES, ICP-AES and SEM/EDS for the study of phytate chelating treatments used on iron gall ink damages manuscripts. J Anal At Spectrom 2011;26:2434-41.

[12] Reissland B. Ink corrosion aqueous and non aqueous treatment of paper objects - state of the art. Restaurator 1999;20:167-80.

[13] Hahn $O$, Wilke $M$, Wolff $T$. Influence aqueous calcium phytate/calcium hydrogen carbonate treatment on the chemical composition of iron gall inks. Restaurator 2008;29:235-50.

[14] Rouchon V, Burgaud C, Nguyen TP, Eveno M, Pichon L, Salomon J. Iron gall ink aqueous treatments: measurement of elemental changes by proton induced X-ray emission. PapierRestaur 2008;9:18-28.

[15] Rouchon V, Desroches M, Duplat V, Letouzey M, Stordiau-Pallot J. Methods of aqueous treatments: the last resort for badly damaged iron gall ink manuscripts. J Paper Conserv 2012;13:7-13.

[16] Bray WC, Livingston RS. The catalytic decomposition of hydrogen peroxide in a bromine-bromide solution, and a study of the steady state. J Am Chem Soc 1923;45:1251-71.

[17] Mamou A, Rabani J, Behar D. Oxidation of aqueous Br- by $\mathrm{OH}$ radicals studied by pulse-radiolysis. J Phys Chem 1977;81:1447-8.

[18] Can ZS, Gurol MD, Iwa. Effect of bromide ions on formaldehyde formation during ozonation of drinking waters. London: I W A Publishing; 2001.

[19] De Laat J, Le TG. Effects of chloride ions on the iron(III)-catalyzed decomposition of hydrogen peroxide and on the efficiency of the Fenton-like oxidation process. Appl Catal B Environ 2006;66:137-46.

[20] Bogaard J, Morris HR, Whitmore PM. A method for the aqueous deacidification of oxidized paper. J Am Inst Conserv 2005;44:63-74.
[21] Malesic J, Kolar J, Strlic M, Polanc S. The use of halides for stabilisation of iron gall ink containing paper - the pronounced effect of cation. e-PS 2005; $2: 13-8$.

[22] Malesic J, Kolar J, Strlic M, Polanc S. The influence of halide and pseudo-halide antioxidants in Fenton-like reaction systems. Acta Chim Slov 2006;53:450-6.

[23] Kolar J, Strlic M, Budnar M, Malesic J, Selih VS, Simcic J. Stabilisation of corrosive iron gall inks. Acta Chim Slov 2003;50:763-70.

[24] Kolar J, Mozir A, Balazic A, Strlic M, Ceres G, Conte V, et al. New antioxidants for the treatment of transition metal containing inks and pigments. Restaurator 2008;29:184-98.

[25] Ceres G, Conte V, Mirruzzo V, Kolar J, Strlic M. Imidazolium-based ionic liquids for the efficient treatment of iron gall inked papers. ChemSusChem 2008;1:921-6.

[26] Page DH, Scallan MA, Middelton SR, Zou X. Method for the deacidification of papers and books. In: Patent US, editor. USA: Pulp and Paper Research Institute of Canada; 1995.

[27] Hanus J, Minarikova J. Deacidification without equipment and money dream or reality? In: Conservation ICf, editor. 13th Triennial meeting, ICOMCC. Rio de Janeiro: James and James Ltd.; 2002. p. 603-8.

[28] Hansen BV. Study of interleaving as a mean to reduce ink corrosion in manuscripts. In: Kolar J, Strilic M, Wouters I, editors. ICCOM-CC graphic document meeting. Ljubljana: National and University Library; 2004. p. 30-1.

[29] Hansen BV. Improving ageing properties of paper with iron gall ink by interleaving with papers impregnated with alkaline buffer and antioxidant. Restaurator 2005;26:190-202.

[30] Malesic J, Kocar D, Fabjan AB. Stabilization of copper- and iron-containing papers in mildly alkaline environment. Polym Degrad Stab 2012;97:118-23.

[31] Ohlsson A, Rydin S. Washing of pulps, part 2. The sorption of Na, Mg and Ca on kraft pulp. Svensk Papper 1975;78:549-53.

[32] ISO 483. Plastics - small enclosures for conditioning and testing using aqueous solutions to maintain the humidity at a constant value 2005 .

[33] TAPPI T 441. Test Cobb: water absorptiveness of sized (non-bibulous) paper and paperboard (Cobb test) 2009.

[34] ISO 5630-3. Paper and board - accelerated ageing - part 3: moist heat treatment at $80^{\circ} \mathrm{C}$ and $65 \%$ relative humidity 1996 .

[35] TAPPI T 231. Zero-span breaking strength of pulp (dry zero-span tensile) 2007.

[36] Jerosch H, Lavedrine B, Cherton J-C. Study on the correlation between SEC and mechanical tests of different paper types for degradation state evaluation. Restaurator 2002;23:222-38.

[37] NF Q 03-005. Essais des papiers, cartons et pâtes, détermination du pH des extraits aqueux 1980.

[38] ISO 12830. Paper, board and pulps - determination of acid-soluble magnesium, calcium, manganese, iron, copper, sodium and potassium 2011.

[39] Stephens CH, Barret T, Whitmore PM, Wade JA, Mazurek J, Schilling M. Composition and condition of naturally aged papers. J Am Inst Conserv 2008;47:201-15

[40] Hill AG, Bishop E, Coles LE, McLauchlan EJ, Meedle W, Pater MJ, et al. General method for the determination of iron with 4,7-diphenyl-1,10-phenanthroline (bathophenanthroline). Analyst 1978;103:521-4.

[41] Clark LJ. Iron(II) determination in the presence of iron (III) using 4,7-diphenyl1,10-phenanthroline. Anal Chem 1962;34:348.

[42] Neevel JG, Reissland B. Bathophenanthroline indicator paper. PapierRestaur 2005;6:28-36.

[43] Neevel JG. Application issues of the bathophenanthroline test for iron(II) ions. Restaurator 2009;30:3-15.

[44] Jacobi E, Reissland B, Phan Tan Luu C, Van Velzen B, Ligterink F. Rendering the invisible visible. J Paper Conserv 2011;12:25-34.

[45] Banik G, Bruckle I. Paper and water. Hong Kong: Elsevier; 2011.

[46] Shahani CJ, Harrison G. Spontaneous formation of acids in the natural aging of paper. In: Daniels V, Donnithorne A, Smith P, editors. Works of art on paper books, documents and photographs: techniques and conservation. Baltimore: International Institute for Conservation; 2002. p. 189-92.

[47] Neevel JG. The behaviour of iron and sulphuric acid during iron-gall ink corrosion. ICOM-CC meeting. Lyon 1999528-33.

[48] Remazeilles C, Quillet V, Calligaro T, Dran JC, Pichon L, Salomon J. PIXE elemental mapping on original manuscripts with an external microbeam. Application to manuscripts damaged by iron-gall ink corrosion. Nucl Instrum Methods Phys Res Sect B Beam Interact Mater At 2001;181:681-7. 